\title{
Non-Dairy Probiotics - An Emerging Trend in Health Care Products
}

\author{
Saadiya, A. Rouf*, Tabeen Jan and Poonam Sharma \\ Division of Food Science and Technology, Sher-e-Kashmir University of Agricultural Science \\ and Technology Shalimar-190025, India \\ *Corresponding author
}

\begin{tabular}{|c|c|}
\hline & B S T R A C T \\
\hline Keywords & \multirow{3}{*}{$\begin{array}{l}\text { The beneficial effects of consuming probiotics wouldn't have been possible without the } \\
\text { extensive research for the past two decades. However, due to enhanced awareness and } \\
\text { health consciousness among today's population, there is an emerging trend of counterparts } \\
\text { and substitutes for dairy probiotics. Globally, the commercial market of dairy probiotics is } \\
\text { on boom, however, the allergic reactions associated with the dairy ingredients and lactose } \\
\text { intolerance in people has resulted in the extensive research and development of non-dairy } \\
\text { probiotics, which prove to be beneficial for health conscious and allergy vulnerable } \\
\text { population. Non-dairy probiotics have geared up in the market due to their wide } \\
\text { acceptability regarding taste, consumption benefits and cost effectiveness, besides the } \\
\text { satisfactory nature of the non-dairy probiotic strains has been an important factor for their } \\
\text { sustainability and growth. Even though dairy probiotics have world over market, the } \\
\text { emerging trend of the non-dairy probiotics has lead to enhanced acceptability regarding the } \\
\text { beneficial health implications. }\end{array}$} \\
\hline Article Info & \\
\hline & \\
\hline
\end{tabular}

\section{Introduction}

Probiotics have been in use for the benefit of humans since the time the consumption of fermented milk and milk products has started. Probiotics are 'live microorganisms which when administered in adequate amounts confer a health benefit on the host (FAO/WHO, 2002). The history of probiotics dates back to the times when Elie Metchnikoff a Russian scientist postulated that lactic acid bacteria (LAB) offer health benefits that promote longevity. He suggested that "intestinal autointoxication" could be suppressed by modifying the gastrointestinal microflora by replacing toxic producing proteolytic microbes such as Clostridium with useful microbes. Lilly and Stillwell coined the term "probiotics" in1965 and defined probiotics as microbially derived factors that accentuate the growth of other organisms. In 1989, Roy Fuller introduced the idea that probiotics have a beneficial effect on the host. Probiotics are able to be formulated into different types of products, including foods, drugs, and dietary supplements. In addition to some species of Bifidobacterium, and Lactobacillus, some yeasts like Saccharomyces cerevisiae and Bacillus species are also classified as probiotics. Lactic acid bacteria which are in use for food preservation by fermentation process for a 
number of years, serve enormous number of functions by acting as agents for food fermentation besides potentially having multiple health benefits.

\section{Health claims}

Probiotics are used to assist the natural gut microflora of humans. Some probiotic preparations are used to prevent diarrhoea caused by antibiotics, or as part of the treatment for antibiotic-related dysbiosis. Several studies have confirmed probiotic effects on a variety of gastrointestinal disorders, including inflammatory bowel disease (IBD), irritable bowel syndrome (IBS), and immune enhancement Probiotics have also been thoroughly studied in relation allergies like atopic eczema and liver cirrhosis. Many investigations have also been done regarding the suppression of Helicobacter pylori infection by addition of selected strains to food products (Gotcheva $e t$ al., 2002; Nomoto, 2005; Imasse et al., 2007; Shah 2007; Vijayendra and Gupta, 2012). In modern health care regime, probiotics are added to curd, yoghurt and other fermented dairy products (Laroia and Martin 1991; Penna et al., 2007; Vijayendra and Gupta 2013) and make those to be used as functional foods (Table 1).

\section{Role of probiotics in human health}

Susceptibility of humans to many diseases due to environmental effect, food patterns and infections lead to the studies about the use of probiotics as remedial agents. Probiotics play an important role in averting or at least subsiding various diseases. For example, Acute diaherroea in children that is mainly caused by rotaviruses infections. The probiotic strains of Bifidobacterium lactis, Lactobacillus delbruecki Lactobacillus reuteri, subsp. Bulgaricus, Strptococcus thermophiles and, Lactobacillus rhamnosus
$G G$, besides having therapeutic effect also have preventive effect on the apparition of acute diarrhoea in children.

Most often, antibiotic therapy results in diarrhoea due to disturbance of natural balance of intestinal microflora which leads to quick growth of Clostridium difficile. Probiotic strains like Saccharomyces boulardii GG, Lactobacillus acidophilus, Lactobacillus rhamnosus and Lactobacillus delbruecki subsp. Bulgaricus during antibiotic therapy, decreases the prevalence of diarrhoea by 52 $\%$. Besides, Non-degraded lactose induces convulsions, flatulence, diarrhea and nausea. In fermented dairy products, the concentration of lactose is significantly lower besides, probiotic variety of fermented dairy products also contains microbial $\beta$-galactosidase (Fooks et al., 1999), upon consumption of which lactose intolerance lowers down considerably. Casein, calcium-phosphate and lactate of fermented dairy products neutralize gastric acid, microbial $\beta$-galactosidase in the active form comes to a small intestine and the symptoms of the illness are made oblivious (Pochart et al., 1989). $\quad \beta$-galactosidase contained in yoghurt is enough to digest 50 $100 \%$ of $20 \mathrm{~g}$ of consumed lactose (Miller et al., 2007).

Many investigations have resulted in conclusions that confirm the effects of probiotic cultures on the immune system. It has been documented that probiotic bacteria are able to enhance both natural and acquired immunity by increasing phagocytosis, and also increasing levels of immunoglobulins. Two probiotic strains have been developed with a particular focus on their enhancing effects on immune responses vis-à-vis Bifidobacterium lactis and Lactobacillus rhamnosus and their ability to enhance natural immune function in healthy people has been demonstrated in several studies (Fuller et al., 2008). In1980's, the hygiene hypothesis was proposed by 
Strachan that clearly emphasized the role of microorganisms in atopy prevention. Pelto et al., established that Lactobacillus rhamnosus GG results in immunostimulatory effect in healthy adults. Probiotics have also been used successfully in the management of atopic eczema in infants. When pregnant ladies and the postnatal mothers, or the infants who are given Lactobacillus rhamnosus GG fortified products for 6 months, reduced the frequency of atopic to half (Delcenserie et al., 2010).

Most of the fermented milk products have been promoted as cancer preventing foods. Studies suggest that colon cancer is associated with a high-fat diet. The high fat diet potentially amplify bile acid turnover and can lead to an increased quantity of bile acids in the colon which affects the metabolism of the gut microflora. Brady et al., did animal studies over a period of 10 years that threw light directly at the promising relationship between consumption of probiotics and development of colon cancer. They found that evidently probiotics have an inhibitory effect on the development of carcinogenic lesions and tumors in animal models. In Japan, a study was conducted that exhibited the significant effect of continous intake of lactic acid bacteria on lowering the risk of bladder cancer (Rafter, 2004). Investigations regarding effect of lactic acid bacteria on constipation have exhibited eloquent results in healthy but constipated adults. Addition of strains of Bifidobacterium longum BB536 to the diet of constipated females resulted in a remarkable improvement in bowel movements and mitigating the constipation issues, besides this, the same strain has a positive effect on defecation frequency for elderly people (Ouwehand et al., 2002).

Above all, there are several results of the investigations exhibiting for the cholesterol lowering effects of probiotics. Nevertheless numerous studies have demonstrated impressive effects of probiotics in reducing cholesterol levels in both animals and humans, controversial results have surfaced. Hatakka et al., (2008) reported that the regulation of $L$. rhamnosus LC705 for 4 weeks did not influence blood lipid profiles in 38 men with average cholesterol levels of $6.2 \mathrm{mmol} / \mathrm{L}$ (240 $\mathrm{mg} / \mathrm{dL})$. There is a need for large-scale clinical trials, determination of ability, and other critical indices to provide the important scientific evidence required to ascertain effectuality of the progressively increasing use of probiotics.

\section{Why non-dairy probiotics?}

Although probiotics are proven to be boon for mankind, a recent trend of non- dairy probiotics has surfaced extraordinarily. Nondairy probiotic products have gathered a global importance due to the ongoing swing of vegetarianism and also due to an exorbitant prevalence of lactose intolerance in large population all over the globe. In current sales of probiotics in the world, $78 \%$ sales are delivered through yogurt. Fruit juices, desserts, and cereal-based products featuring probiotics may be other suitable media for delivering probiotics (Cargill, 2009).

With the help of advanced technologies, alteration in some structural characteristics of fruits and vegetables matrices by manipulating their constituents in a regulated way such as modification of $\mathrm{pH}$, culture media fortification, besides others (Betoret et al., 2003). These modifications, convert these conventional food products deal substrates for probiotics culture, as they already contain beneficial nutrients, but lacking the dairy allergens that might prevent consumption by the population suffering from dairy allergies (Sheehan et al., 2007). Lactose intolerance, high cholesterol levels, and some milk proteins which may prove to be allergens are the major limitations related to the intake of 
dairy products, which makes it necessary to pave way for the development of new nondairy probiotic food products.

Currently most probiotic foods available are dairy based, but considering the consumer preference that is inclined towards the plant based dietary supplements, in which cholesterol is either absent or present negligibly. The market for functional foods is in its baby stage in most of the countries; however, product innovation in different areas, such as beverages, bakery and probiotics, is apparent, with trends generally following those of the U.S. and U.K. (Luckow et al., 2004) Asian diets are relatively low in non-vegetarian and dairy based foods, while botanical foods contribute the maximum of their daily food intake. Besides dietary habits, lactose intolerance in Asian population discourages them from consuming milk and allied products. Taking the above mentioned facts into consideration cereals, fruits and vegetables turnout to be promising products, where the viable probiotic flora can pave their way, in the developing as well as the developed countries.

\section{Health risks associated with fermented dairy foods}

In spite of numerous health benefits, there are certain health risks associated with dairy based probiotic foods. These risks mainly include lactose intolerance, milk protein allergies, high fat and high cholesterol content. These risks are elaborated below.

\section{Lactose intolerance}

Lactose intolerance (LI) also known as lactose mal absorption is a condition characterized by the inability to digest lactose due to low levels of lactase enzyme activity. Activity of lactase enzyme is dependent on a large number of factors such as race, age, soundness of the small intestinal membrane and small intestinal transit time (Table 2).

\section{Milk protein allergy}

Atopic dermatitis (AD) is a disease that is frequently associated with food allergy in children (Ricci et al., 2006; Johnke et al., 2007). Various investigations have determined that the consumption of probiotics lowers the occurrence of atopic dermatitis (Reid and Kirjaivanen, 2005). With selective strains of probiotics, various studies have reported a lowering of signs and symptoms in these patients. Some studies have also shown that the probiotic supplementation has no remarkable effect on the symptoms related to infantile allergies (Brouwer et al., 2006).

\section{High fat and cholesterol}

Fat content in milk depends upon the source from which it is obtained. Cow milk has approximately 4-5\% fat, whereas, buffalo milk contains approximately 7-8\%. Large amount of milk consumption risk a consumer to increased level of total cholesterol and LDL-cholesterol contents in the blood that proved to be a major risk factor for coronary heart disease fat (Levy and Feinleib, 1980. This risk can be decreased by lowering the quantity of low-density lipoproteins (LDL) cholesterol by lowering the quantity of saturated fats in the diet. According to a study decrease in the serum cholesterol level at the end of 30 days in rats fed with probiotic dahi and probiotic yoghurt, containing $L b$. acidophilus and Bifidobacterium bifidum demonstrate the hypocholesterolaemic effect of the probiotic cultures (Vijayendra and Gupta 2012).

\section{Development of non-dairy probiotics}

Innovation is today's business mantra. Experts proclaim that the only hope for survival of any 
business is the ability to continue innovating. Considering this fact, the development of new non-dairy probiotic food products turns out to be enormously challenging, as it has to achieve the expectations of consumer for products that are healthy as well as tasty (Shah 2007). Developing a new Milk-free probiotic food is a cost intensive process. Food companies have largely funded research for new food product formulations, however, the stakes are higher for products where lactose is absent, (Walzem 2004). The high reported failure rates for new international functional foods suggest a failure to manage the customer knowledge effectively, as well as a lack of knowledge management between the functional disciplines involved in the new product development process (Jousse, 2008).

The food industry takes into consideration many variables to develop or rebuilt milk free probiotic products, such as sensory attributes, stability, cost, and functional properties. Consumption of beverages and food products that contain probiotic microflora is a globally growing trend (Verbeke, 2005). Mayonnaise, soymilk, meats, baby foods, ice creams, fruit drinks, vegetable drinks, and many others have already been proposed (Champagne et al., 2005; Homayouni et al., 2008).There is a wide variety of traditional non-dairy foods developed around the world. Many of them are non-alcoholic beverages manufactured with cereals as main raw materials. There are different non-dairy based probiotic foods developed, some of which are briefly taken account of (Table 3).

\section{Cereal and pulses based probiotic products}

A multitude of non-dairy fermented cereal products has been created throughout history for human nutrition, but only recently probiotic characteristics of microorganisms involved in traditional fermented cereal foods have been reported (Table 4).

\section{Boza}

A traditional fermented beverage made from cereals is a cold beverage consumed in Bulgaria, Albania, Turkey, and Romania. Microbial identification of Bulgarian boza determines that it consists of yeasts and lactic acid bacteria (Gotcheva et al., 2000).

\section{Bushera}

A traditional cereal-based beverage made in the Western highlands of Uganda.

\section{Mahewu (amahewu)}

It is a sour beverage prepared from corn meal, mostly available in Africa and some Persian Gulf countries.

Table.1 Definitions used by the international scientific associations for probiotics, prebiotics and synbiotics

\footnotetext{
Probiotics: Live microorganisms that confer a health benefit on the host when administered in adequate amounts

Prebiotics: Selectively fermented ingredients that result in specific changes in the composition and/or activity of the gastrointestinal microbiota, thus conferring benefit(s) upon host health

Synbiotics: Products that contain both probiotics and prebiotics
} 
Table.2 Population of different countries affected by lactose intolerance

\begin{tabular}{|l|l|l|}
\hline & Country & \% Population afflicted by lactose - intolerance \\
\hline $\mathbf{1}$ & France & 30 to 40 \\
\hline $\mathbf{2}$ & Germany & 15 to 20 \\
\hline $\mathbf{3}$ & Russia & 20 to 30 \\
\hline $\mathbf{4}$ & Finland & 15 to 20 \\
\hline $\mathbf{5}$ & Sweden & $<5$ \\
\hline $\mathbf{6}$ & Greece & 70 to 80 \\
\hline $\mathbf{7}$ & Ethiopia & 80 to 90 \\
\hline $\mathbf{8}$ & Nigeria & 80 to 90 \\
\hline $\mathbf{9}$ & China & 90 to 100 \\
\hline $\mathbf{1 0}$ & Japan & 95 to 100 \\
\hline $\mathbf{1 1}$ & India & 60 to 65 \\
\hline $\mathbf{1 2}$ & Israel & 70 to 80 \\
\hline $\mathbf{1 3}$ & USA (white) & 10 to 15 \\
\hline $\mathbf{1 4}$ & USA (black) & 65 to 70 \\
\hline $\mathbf{1 5}$ & Mexico & 50 to 60 \\
\hline $\mathbf{1 6}$ & Uruguay & 60 to 65 \\
\hline
\end{tabular}

Source: Alm (2002).

Table.3 List of some non-dairy probiotic products developed recently

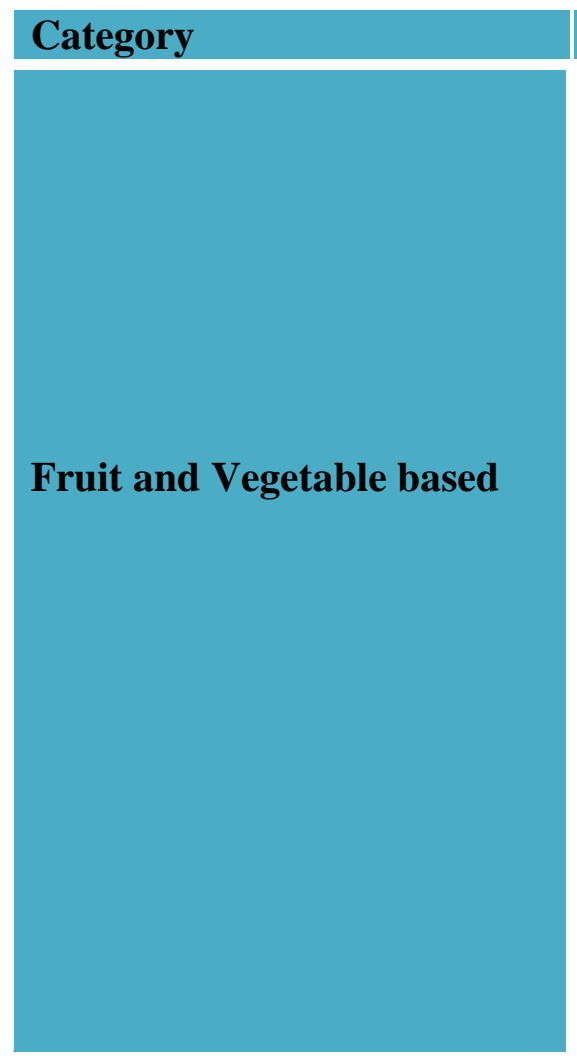

\begin{tabular}{|l|}
\hline Product \\
\hline Vegetable-based drinks \\
\hline Fermented banana pulp \\
\hline Fermented banana \\
\hline Beets-based drink \\
\hline Tomato-based drink \\
\hline Many dried fruits \\
\hline Green coconut water \\
\hline Peanut milk \\
\hline Cranberry, pineapple, and orange \\
juices \\
\hline Ginger juice \\
\hline Grape and passion fruit juices \\
\hline Cabbage juice \\
\hline Carrot juice \\
\hline Noni juice \\
\hline Onion \\
\hline Probiotic banana puree \\
\hline $\begin{array}{l}\text { Non fermented fruit juice } \\
\text { beverages }\end{array}$ \\
\hline
\end{tabular}

\section{Refrence}

Lambo et al., (2005)

Tsen et al., (2004)

Tsen et al., (2009)

Yoon et al., (2005)

Yoon et al., (2004)

Betoret et al., (2003)

Prado et al., (2008)

Mustafa et al., (2009)

Sheehan et al., (2007)

Chen et al., (2008)

Saarela et al., (2006)

Yoon et al., (2006)

Nazzaro et al., (2008)

Wang et al., (2009)

Roberts and Kidd (2005)

Tsen et al., (2009)

Renuka et al., (2009) 


\begin{tabular}{|c|c|c|}
\hline & Blackcurrant juice & Luckow and Delahunty (2004) \\
\hline & Plum juice & Sheela and Suganya (2012) \\
\hline & Cashew apple juice & Pereira et al., (2011) \\
\hline & Table olives & De Bellis et al., (2010) \\
\hline & $\begin{array}{l}\text { Fruit juices (mango, sapota, } \\
\text { grape) }\end{array}$ & Vijaya Kumar et al., (2013) \\
\hline \multirow{24}{*}{ Cereals and Pulses based } & $\begin{array}{l}\text { Non fermented soy-based frozen } \\
\text { desserts }\end{array}$ & Heenan et al., (2004) \\
\hline & Fermented soymilk drink & Donkor et al., (2007) \\
\hline & $\begin{array}{l}\text { Soy-based stirred yogurt-like } \\
\text { drinks }\end{array}$ & Saris et al., (2003) \\
\hline & Soy based products & Bedani et al., (2013) \\
\hline & Soyghurt & Bedani et al., (2014) \\
\hline & Soy curd & $\begin{array}{l}\text { Roopashri and Varadaraj } \\
\text { (2014) }\end{array}$ \\
\hline & $\begin{array}{l}\text { Soy product fermented with } \\
\text { Kefir }\end{array}$ & Baú et al., (2014) \\
\hline & Cereal-based puddings & Helland et al., (2005) \\
\hline & Rice-based yogurt & $\begin{array}{l}\text { Boonyaratanakornkit } \\
\text { Wongkhalaung (2000) }\end{array}$ \\
\hline & Oat-based drink & Angelov et al., (2006) \\
\hline & Oat-based products & Martensson et al., (2002) \\
\hline & Oat milk & Bernat et al., (2014) \\
\hline & Oat, barley, and malt based & Salmerón et al., (2014) \\
\hline & Yosa (oat-bran pudding) & Blandino et al., (2003) \\
\hline & $\begin{array}{l}\text { Mahewu (fermented maize } \\
\text { beverage) Maize-based beverage }\end{array}$ & McMaste et al., (2005) \\
\hline & & Wacher et al., (2000) \\
\hline & $\begin{array}{l}\text { Wheat, rye, millet, maize, and } \\
\text { other cereals fermented probiotic } \\
\text { beverages }\end{array}$ & Blandino et al., (2003) \\
\hline & Malt-based drink & Kedia et al., (2007) \\
\hline & Boza (fermented cereals) & Moncheva et al., (2003) \\
\hline & $\begin{array}{l}\text { Maize, sorghum, and millet malt } \\
\text { fermented probiotic beverages }\end{array}$ & Blandino et al., (2003) \\
\hline & $\begin{array}{l}\text { Millet or sorghum flour } \\
\text { fermented probiotic beverage }\end{array}$ & Muyanja et al., (2003) \\
\hline & Mixed cereal beverage & Rathore et al., (2012) \\
\hline & Bread and baked products & Côté et al., (2013) \\
\hline & Sorghum based 'Sorghurt' & Sanni et al., (2013) \\
\hline \multirow[t]{2}{*}{ Sorghum based } & $\begin{array}{l}\text { Pseudo cereals (amaranth, } \\
\text { buckwheat) }\end{array}$ & Monika et al., (2013) \\
\hline & As an edible film on pan bread & Soukoulis et al., (2014) \\
\hline
\end{tabular}

Source: Dr. vijaysivakumar et al., March 2015 
Table.4 Comparative account of dairy and non-dairy probiotic foods

\begin{tabular}{|l|}
\hline Parameter \\
\hline Lactose intolerance \\
\hline Calcium availability \\
\hline High fat \\
\hline Cholesterol content \\
\hline Dietary fibre \\
\hline Digestibility \\
\hline Survival rate of probiotics \\
\hline Flavour (diacetyl/acetaldehyde) \\
\hline Phyto-chemicals \\
\hline Isoflavons \\
\hline
\end{tabular}

Pozol

Prepared from cocoa and cornmea, it is a refreshing beverage, widely produced in the Southeastern Mexico (Prado and others 2008a).

\section{Fruit and vegetable based probiotic products}

Despite potential sensory challenges, there is a genuine interest in the development of fruitjuice based functional beverages, fortified with the probiotic and prebiotic ingredients. The fruit juices have been suggested as an ideal medium for the functional health ingredients because they inherently contain beneficial nutrients, they have taste profiles that are pleasing to all the age groups, and because they are perceived as being healthy and refreshing (Tuorila and Cardello, 2002). The fruits and vegetables are rich in the functional food components such as minerals, vitamins, dietary fibres, antioxidants, and do not contain any dairy allergens that might prevent usage by certain segments of the population (Luckow and Delahunty, 2004).

\section{Coconut milk yogurt}

Coconut milk yogurt is a delicious, dairy-free probiotic yoghurt like food product.
Kimchi spicy fermented cabbage

Kimchi is a spicy fermented cabbage, and is popular in Korea as a non-dairy side dish that is rich in probiotics.

This food also contains healthy servings of iron, folate, and vitamins $\mathrm{A}, \mathrm{C}, \mathrm{K}$, and $\mathrm{B} 6$.

\section{Sauerkraut}

Sauerkraut is also a fermented cabbage that can be used to get non-dairy probiotics and digestive enzymes in diet.

\section{Fermented pickles}

Pickles are an excellent source of probiotics.

However, the pickles should be naturally fermented instead of artificially acidified ones.

\section{Umeboshi plums}

Widely available in Japan for their healing and therapeutic properties,

Umeboshi plums also called Japanese salty plums or ume plums - are a source of probiotics but are less known in the Western world. 


\section{Soy based probiotic food products}

\section{Tempeh meat substitute}

Tempeh is made from cooked and fermented soybeans and has a firm texture and nutty flavor not only is it dairy-free, but it's also high in protein and calcium, and an excellent source of probiotics. It is used as a meat substitute in many types of dishes such as tacos, chili, or a vegetarian stir-fry. Some brands of tempeh are also a good source of gluten-free probiotics

\section{Miso paste}

Miso is a traditional Japanese condiment made from either fermented rye, soybeans, rice, or barley. It is a lovely source of probiotics that includes Lactobacilli and Bifidobacteria. Commonly enjoyed as miso soup, it can also be used to make a delicious salad dressing.

\section{Natto fermented soybeans}

Much like tempeh, natto is made of fermented soybeans and contains bacillus, a healthy bacteria. It's also an excellent source of protein and provides several vitamins and minerals including iron, copper, magnesium, calcium, potassium, zinc, phosphorus, selenium, and vitamins $\mathrm{C}$ and $\mathrm{K}$. Traditionally eaten as a breakfast food, natto can be consumed by itself, or it can be added it to virtually any dish.

\section{Non-dairy probiotic drinks}

\section{Non-dairy kefir drink}

A lightly fermented drink, kefir contains up to 30 microorganism strains, which gives it a higher level of probiotics than yogurt. Although dairy Kefir exists, any milk can be used to create it, including coconut milk, almond milk, and others. Kefir and the associated probiotics have been shown to fight against harmful bacteria and Candida yeast and normalize gut function.

\section{Kombucha probiotic tea drink}

Kombucha is a dairy-free probiotic drink in the form of black tea. This delicious beverage is fermented by a combination of bacteria and yeast and it contains several types of probiotics including Gluconacetobacter, Lactobacillus, Acetobacter, and Enterococcus faecium bacterial strains as well as probiotic yeasts like Zygosaccharomyces. Kombucha is a refreshing and healthy replacement for soda or carbonated beverages.

\section{Future perspectives and challenges}

Non-dairy product preparation is necessities in today's world, however, the technological feasibility, development of technologies that are adaptable with development are not in line with each other. The ongoing research in this field is being carrying out at remarkable rate, however, it still is unconvincing when compared with the production of their dairy counterparts. Development of new, cost effective and adaptable technological moulds is an outrageous necessity to bring the nondairy probiotic food products in line with their demand with today's population. While developing the non-dairy probiotics, certain important factors like stability, sensory attributes related to taste, consumer attraction and price factors need to be taken into consideration because these attributes play a key role is success of the product at commercial levels. As far as the technological issues that have an impact on the survival of probiotic strains throughout the manufacturing process and storage tenure should also be taken care of while preparing new probiotic products. Exploration of nondairy probiotic products can be enhanced by 
investigating their benefits for the mankind. An idea regarding the preparation of synbiotics by combining conventional prebiotics with non-dairy probiotics can also be explored for further advancement in this area.

\section{References}

Alm L. 2002. Lactose intolerance. In: Roginsky H, Fuquay JW, Fox PF, editors. Encyclopedia of dairy sciences. London, U.K.: Academic Press. p 1533-7.

Angelov A, Gotcheva V, Kuncheva R, Hrstozova T (2006) Development of a new oat-based probioticdrink. Int $\mathrm{J}$ Food Microbiol 112:75-80

Baú TR, Garcia S, Ida EI (2014) Evaluation of a functional soy product with addition of soy fiber and fermented with probiotic kefir culture. Braz Arch Biol Technol 57:402-409

Bedani R, Rossi EA, Saad SMI (2013) Impact of inulin and okara on Lactobacillus acidophilus La-5 and Bifidobacterium animal is Bb12 viability in a fermented soy product and probiotic survival under in vitro simulated gastrointestinal conditions. Food Microbiol 34: 382 389

Bedani R, Vieira ADS, Rossi EA, Saad SMI (2014) Tropical fruit pulps decreased probiotic survival to in vitro gastrointestinal stress in synbiotic soy yoghurt with okara during storage. LWT-Food Sci Technol 55:436-443

Betoret N, Puente L, Diaz MJ, Pagan MJ, Garcia MJ, Gras ML (2003) Development of probiotic enriched dried fruits by vacuum impregnation. J Food Eng 56:273-277

Brouwer ML, Wolt-Plompen SA, Dubois AE, van der Heide S, Jansen DF, Hoijer MA, Kauffman HA, Duiverman EJ (2006) No effect of probiotics on atopic dermatitis in infancy: a randomized placebo controlled trial. Clin Exp Allergy 37:899-906

Cargill. 2009. Cargill beverage concepts will address consumer demands for health, taste and texture at IFT 2008. Available from: http://www.cargill.com/newscenter/news-releases/2008/NA3007612. jsp Accessed Jul 20, 2009.

Champagne CP, Roy D, Gardner N. 2005. Challenges in the addition of probiotic cultures to foods. Crit Rev Food Sci Nutr 45:61-84.

Chen INCC, Wang CY, Chang TL (2008) Lactic fermentation and antioxidant activity of Zingiberaceae plants in Taiwan. Int J Food Sci Nutr 22:1-10

Chen YP, et al., "Lactobacillus kefiranofaciens M1 isolated from milk kefir grains ameliorates experimental colitis in vitro and in vivo." J Dairy Sci. 2012; 95(1), 63-74.

Côté J, Dion J, Burguière P, Casavant L, Eijk VJ (2013) Probiotics in bread and baked products: a new product category. Cereal Foods World 58:293-296

De Bellis P, Valerio F, Sisto A, Lonigro SL, Lavermicocca P (2010) Probiotic table olives: microbial populations adhering on olive surface in fermentation sets inoculated with the probiotic strain Lactobacillus paracasei IMPC2.1 in an industrial plant. Int J Food Microbiol 140:6-13

De Preter V, Vanhoutte T, Huys G, Swings J, De Vuyst L, et al., (2007) Effects of Lactobacillus casei Shirota, Bifidobacterium breve, and oligofructose-enriched inulin on colonic nitrogen-protein metabolism in healthy humans. Am J Physiol Gastrointest Liver Physiol 292: 358-368

Delcenserie, V., Martel, D., Lamoureux, M., Amiot, J., Boutin, Y. and Roy, D. 2010. Immunomodulatory Effects of Probiotics in the Intestinal Tract. 
Current Issues in Molecular Biology 10: 37-54

Donkor ON, Henriksson A, Vasiljevic T, Shah NP (2007) $\alpha$-Galactosidase and proteolytic activities of selected probiotic and dairy cultures in fermented soymilk. Food Chem 104:10-20

Dubravka Samaržija et al., Probiotic bacteria in prevention and treatment of diarrhea Ebel B, Lemetais G, Beney L, Cachon $\mathrm{R}$, Sokol $\mathrm{H}$, Langella $\mathrm{P}$, Gervais $\mathrm{P}$ (2014) Impact of probiotics on risk factors for cardiovascular diseases. A review. Crit Rev Food Sci Nutr 54:175189

Emiliano J. Quinto, Pilar Jiménez, Irma Caro, Jesús Tejero, Javier Mateo, Tomás Girbés Probiotic Lactic Acid Bacteria: A Review.

Fernandez ML, Roy S, Vergara-Jimenez M (2000) Resistant starch and cholestyramine have distinct effects on hepatic cholesterol metabolism in Guinea pigs fed a hypercholesterolemic diet. Nutr Res 20: 837-849.

Fooks, L.J., Fuller, R., Gibson, G.R. (1999): Prebiotics, probiotics and human gut microbiology, International Dairy Journal 9 (1), 53-61

Francisco Guarner et al., World Gastroenterology Organisation Global Guidelines Probiotics and prebiotics, October 2011

Fujiwara S, Seto Y, Kimura A, Hashiba H (2001) Establishment of orallyadministered lactobacillus gasseri SBT2055SR in the gastrointestinal tract of humans and its influence on intestinal microflora and metabolism.

Fuller R., G. Perdigon and R.A. Rastall, 2008. The Health Benefits of Probiotics and Prebiotics, Gut Flora, Nutrition, Immunity and Health, 46-58

Gallaher CM, Munion J, Hesslink R Jr, Wise J, Gallaher DD (2000) Cholesterol reduction by glucomannan and chitosan is mediated by changes in cholesterol absorption and bile acid and fat excretion in rats. J Nutr 130: 27532759.

Goldin BR, Gorbach SL (1984) The effect of milk and Lactobacillus feeding on human intestinal bacterial enzyme activity. Am J Clin Nutr 39: 756-761.

Gotcheva V, Hristozova E, Hrostozova T, Guo M, Roshkova Z, Angelov A (2002) Assessment of potential probiotic properties of $\mathrm{LAB}$ and yeast strains. Food Biotechnol 16:211-225

Greany KA, Bonorden MJ, Hamilton-Reeves $\mathrm{JM}$, McMullen MH, Wangen KE, et al., (2008) Probiotic capsules do not lower plasma lipids in young women and men. Eur J Clin Nutr 62: 232-237.

Hatakka K, Mutanen M, Holma R, Saxelin M, Korpela R (2008) Lactobacillus rhamnosus LC705 together with Propionibacterium freudenreichii ssp Madsen CS, Janovitz E, Zhang R, Nguyen-Tran V, Ryan CS, et al., (2008) The Guinea pig as a preclinical model for demonstrating the efficacy and safety of statins. J Pharmacol Exp Ther 324: $576-586$.

Heenan CN, Adams MC, Hosken RW, Fleet GH (2004) Survival and sensory acceptability of probiotic microorganisms in a non-fermented frozen vegetarian dessert. LWT Food Sci Technol 37:461-466

Helland MH, Wciklund T, Narvhus JA (2005) Growth and metabolism of selected strains of probiotic bacteria in milk and water-based cereal puddings. Int Dairy J 14:957-965

Hill AM, Fleming JA, Kris-Etherton PM (2009) The role of diet and nutritional supplements in preventing and treating cardiovascular disease. Curr Opin Cardiol 24:433-441 
Homayouni A, Azizi A, Ehsani MR, Razavi SH, Yarmand MS. 2008. Effect of micro encapsulation and resistant starch on the probiotic survival and sensory properties of synbiotic icecream. Food Chem 11:50-5.

Host A (2002) Frequency of cow's milk allergy in childhood. Ann Allergy Asthma Immunol 89:33-37

Imasse K, Tanaka A, Tokunaga K, Sugano H, Ishida H, Takahashi S (2007) Lactobacillus reuteri tablets suppress Helicobacter pylori infection in a double blind randomised placebocontrolled crossover clinical study Kansenshogaku zasshi. J Jpn Assoc Infect Dis 81:387-393

Johnke H, Norberg LA, Vach W, Host A, Andersen KE (2007) Patterns of sensitization in infants and its relation to atopic dermatitis. Pediatr Allergy Immunol 17:591-600

Kedia G, Wang R, Patel H, Pandiella SS (2007) Use of mixed cultures for the fermentation of cereal-based substrates with potential probiotic properties. Process Biochem 42:65-70

Lactobacillus gasseri SBT2055SR in the gastrointestinal tract of humans and its influence on intestinal microflora and metabolism. J Appl Microbiol 90: 343 352

Lambert JM, Bongers RS, de Vos WM, Kleerebezem M (2008) Functional analysis of four bile salt hydrolase and penicillin acylase family members in Lactobacillus plantarum WCFS1. Appl Environ Microbiol 74: 4719-4726.

Lambo AM, Oste R, Nyman MGEL (2005) Dietary fibre infermented oat and barley $\beta$-glucan rich concentrates. Food Chem 85:283-293

Laroia S, Martin JH (1991) Effect of $\mathrm{pH}$ on survival of Bifidobacterium bifidum and Lactobacillus acidophilus in frozen fermented dairy desserts. Cult Dairy Prod J 26:13-21

Levy RI, Feinleib M (1980) Risk factors for coronary artery disease and their management. In: Braunwald E (ed) Heart disease. Saunders WB, Philadelphia, pp 1246-1278

Lewis SJ, Burmeister S (2005) A doubleblind placebo-controlled study of the effects of Lactobacillus acidophilus on plasma lipids. Eur J Clin Nutr 59: 776780.

Lichtman AH, Clinton SK, Iiyama K, Connelly PW, Libby P, et al., (1999) Hyperlipidemia and atherosclerotic lesion development in LDL receptordeficient mice fed defined semipurified diets with and without cholate. Arterioscler Thromb Vasc Biol 19: 1938-1944.

Lin Y, Meijer GW, Vermeer MA, Trautwein EA (2004) Soy protein enhances the cholesterol-lowering effect of plant sterol esters in cholesterol-fed hamsters. J Nutr 134: 143-148.

Liong MT, Shah NP (2005) Acid and bile tolerance and cholesterol removal ability of Lactobacilli strains. J Dairy Sci 88: 55-66.

Liong MT, Shah NP (2006) Effects of a Lactobacillus casei synbiotic on serum lipoprotein, intestinal microflora, and organic acids in rats. J Dairy Sci 89: 1390-1399.

Luckow T, Delahunty C (2004) Which juice is healthier? A consumer study of probiotic non-dairy juice drinks. Food Qual Prefer 15: 751-759

Lye HS, Rusul G, Liong MT (2010) Mechanisms of cholesterol removal by Lactobacilli under conditions that mimic the human gastrointestinal tract. Int Dairy J 20: 169-175.

Lye HS, Rusul G, Liong MT (2010) Removal of cholesterol by Lactobacilli via incorporation and conversion to 
coprostanoL. J Dairy Sci 93: 13831392.

Madsen CS, Janovitz E, Zhang R, NguyenTran V, Ryan CS, et al., (2008) The Guinea pig as a preclinical model for demonstrating the efficacy and safety of statins. J Pharmacol Exp Ther 324: 576 586.

Matricardi PM (2002) Probiotics against allergy: data, doubts, and perspectives. Allergy 57:185-187

McMaste LD, Kokott SJ, Abratt VR (2005) Use of traditional African fermented beverages as delivery vehicles for Bifidobacterium lactis DSM 10140. Int J Food Microbiol 102:231-237

Miller, G.D., Jarvis, J.K., McBean, L.D. (2007): Handbook of dairy foods and nutition, 3. izd., Taylor \& Francis group, New York. Probiotics: Myths or facts about their role in allergy prevention

Monika K, Juraj M,Alzbeta M, Ernest S,Lubomir V (2013) Cereals and pseudocereals as substrates for growth and metabolism of a probioticstrain Lactobacillus rhamnosus GG.J Food NutrRes 52:25-36

Moro G, Arslanoglu S, Stahl B, Jelinek J, Wahn U, Boehm G (2006) A mixture of prebiotic oligosaccharides reduces the incidence of atopic dermatitis during the first six months of age. Arch Dis Child 91:814-819

Mustafa S, Shaborin A, Kabeir BM, Yazid AM, Hakim MN, Khahtanan A (2009) Survival of Bifidobacterium pseudocatenulatum G4 during the storage of fermented peanut milk (PM) and skim milk (SM) products. Afr J Food Sci 3:150-155

Muyanja CMBK, Narvhus JA, Treimo J, Langsrud T (2003) Isolation, characterisation and identification of lactic acid bacteria from bushera: a Ugandan traditional fermented beverage. Int J Food Microbiol 80:201210

Nazzaro F, Fratinni F, Sada A, Orlando P (2008) Synbiotic potential of carrot juice supplemented with Lactobacillus spp. and inulin or fructo oligosaccharides. J Sci Food Agric 88:2271-2276

Nomoto, K. (2005): Prevention of infections by probiotics, Journal of Bioscience and Bioengineering 100 (6), 583-592

Ouwehand, A.C., Lagström, H., Suomalainen, T. and Salminen, S. 2002. Effect of Probiotics on Constipation, Fecal Azoreductase Activity and Fecal Mucin Content in the Elderly. Annals of Nutrition and Metabolism 46:

Patterson JK, Lei XG, Miller DD (2008) The pig as an experimental model for elucidating the mechanisms governing dietary influence on mineral absorption. Exp Biol Med (Maywood) 233: 651664.

PennaALB, Rao-GurramS, BarbosaCa'novasGV (2007) Effect of milk treatment on acidification, physicochemical characteristics, and probiotic cell counts in low fat yogurt. Milchwissenschaft 62:48-52

Pereira DI, Gibson GR (2002) Cholesterol assimilation by lactic acid bacteria and Bifidobacteria isolated from the human gut. Appl Environ Microbiol 68: 46894693.

Pochart, P., Dewit, O., Desjeux, J., Bourlioux, P. (1989): Viable starter culture, betagalactosidase activity, and lactose in duodenum after yogurt ingestion in lactase-deficient humans, American Journal of Clinical Nutrition 49 (5), 828-831.

Prado FC, Lindner JDD, Inaba J, ThomazSoccol V, Brar SK, Soccol CR (2015) Development and evaluation of a fermented coconut water beverage with 
potential health benefits. J Funct Foods 12:489-497

Rafter, J. 2004. The effects of probiotics on colon cancer development. Nutrition Research Reviews 17: 277-284

Rathore S, Salmerón I, Pandiella SS (2012) Production of potentially probiotic beverages using single and mixed cereal substrates fermented with LAB cultures. Food Microbiol 30:239-244

Reddy BS, Watanabe K, Weisburger JH, Wynder EL (1977) Promoting effect of bile acids in colon carcinogenesis in germ-free and conventional F344 rats. Cancer Res 37: 3238-3242.

Reid G, Kirjaivanen P (2005) Taking probiotics during pregnancy. Are they useful therapy for mothers and newborns? Can Fam Physician 51:1477-1479

Renuka B, Kulkarni SG, Vijayanand P, Prapulla SG (2009) Fructo oligosaccharide fortification of selected fruit juice beverages: effect on the quality characteristics. LWT-Food Sci Technol 43:1031-1033

Ricci G, Patrizi A, Baldi E, Menna G, Tabanelli M, Masi M (2006) Longterm follow-upofatopic dermatitis: retrospective analysis of related risk factors and association with concomitant allergic diseases. JAm Acad Dermatol 55:765-771

Roberts JS, Kidd DR (2005) Lactic acid fermentation of onions. FoodSci Technol 38: 2185-2190

Rodrigues KL, et al., "Antimicrobial and healing activity of kefir and kefiran extract." J Antimicrob Agents. 2005; 25(5), 404-408.

Roopashri AN, Varadaraj MC (2014) Hydrolysis of flatulence causing oligosaccharides by $\alpha$-d-galactosidase of a probiotic Lactobacillus plantarum MTCC5422 in selected legume flours and elaboration of probiotic attributes in soy-based fermented product. Eur Food Res Technol.

Saarela M, Virkarjarvi I, Alakomi HL, Matilla PS, Matto J (2006) Stability and functionality of freeze-dried probiotic Bifidobacterium cells during storage in juice and milk. Int Dairy J 16:14771482

Saris PEJ, Beasley S, Tourila H (2003) Fermented soymilk with a monoculture of Lactococcus lactis. Int $\mathrm{J}$ Food Microbiol 81:159-162

Shah NP (2007) Shah NP (2007) Functional cultures and health benefits. Int Dairy J 17: $1262-1277$

Sheehan VM, Ross P, Fitzgerald GF (2007) Assessing the acid tolerance and the technological robustness of probiotic cultures for fortification in fruit juices. Innovative Food Sci Emerg Technol 8:279-284

Sheela T, Suganya RS (2012) Studies on antidiarrhoeal activity of synbiotic plums juice. Int J Sci Res Publ 2:1-5

Shinnick FL, Longacre MJ, Ink SL, Marlett JA (1988) Oat fiber: composition versus physiological function in rats. $\mathrm{J}$ Nutr 118: 144-151.

Simons LA, Amansec SG, Conway P (2006) Effect of Lactobacillus fermentum on serum lipids in subjects with elevated serum cholesterol. Nutr Metab Cardiovasc Dis 16: 531-535.

Sistek D, Kelly R, Wickens K, Stanley T, Fitzharris P, Crane J (2006) Is the effect of probiotic on atopic dermatitis confined to food sensitized children? Clin Exp Allergy 36:629-633

Soukoulis C, Yonekura L, Gan HH, Behboudi-Jobbehdar S, Parmenter C, Fisk I (2014) Probiotic edible film sasanew strategy for developing functional bakery products: the case of pan bread. Food Hydrocoll 39:231-242

Taylor AL, Dunstan JA, Prescott SL (2007) Probiotic supplementation for the first 6 
months of life fails to reduce the risk of atopic dermatitis and increase the risk of allergen sensitization in high-risk children: a randomized control trial. J Allergy Clin Immunol 119:184-191

Tsen JH, L in YP, King VA (2004) Fermentation of banana media by using k-carrageenan immobilized Lactobacillus acidophilus. Int J Food Microbiol 91:215-220

Tsen JH, Lin YP, King AE (2009) Response surface methodology optimisation of immobilized Lactobacillus acidophilus banana puree fermentation. Int J Food Sci Technol 44:120-127

Tuorila H, Cardello AV (2002) Consumer responses to an off-flavor in juicein the presenceof specific health claims. Food Qual Prefer 13: 561-569

Vasudha, S. and Mishra, H. N. Non-dairy probiotic beverages International Food Research Journal 20(1): 7-15 (2013)

Verbeke W. 2005. Consumer acceptance of functional foods: socio-demographic cognitive and attitudinal determinants. Food Qual Pref 16:45-57

Vijayendra SVN, Gupta RC (2012) Assessment of probiotic and sensory properties of dahi and yoghurt prepared using bulk freeze-dried cultures in buffalo milk. Ann Microbiol 62:939947

Vijaysivakumar et al., Journal of Food Science and Technology -Mysore- . March 2015 Trends in dairy and nondairy probiotic products -a review

Walzem RL. 2004, functional foods. Trends in food science technology 15:518

Wang C, Ng CC, Tzeng W, Shyu YT (2009) Probiotic potential of noni juice fermented with lactic acid bacteria and bifidobacteria. Int J Food Sci Nutr 1:19

Yoon KY, Woodamns EE, Hang YD (2004) Probiotication of tomato juice by LAB. J Microbiol 42:315-318

Yoon KY, Woodamns EE, Hang YD (2005) Fermentation of beet juice by beneficial LAB. LWT-Food Sci Technol 38:73-75

\section{How to cite this article:}

Saadiya, A. Rouf, Tabeen Jan and Poonam Sharma. 2018. Non-Dairy Probiotics - An Emerging Trend in Health Care Products. Int.J.Curr.Microbiol.App.Sci. 7(10): 131-145. doi: https://doi.org/10.20546/ijcmas.2018.710.015 